This is the peer reviewed version of the following article: Heaton, Karen Macdonald, Skok, Walter and Kovela, Serhiy (2016) Learning lessons from software implementation projects : an exploratory study. Knowledge and Process Management, 23(4), pp. 293-306 which has been published in final form at http://dx.doi.org/10.1002/kpm.1525 . This article may be used for non-commercial purposes in accordance with Wiley Terms and Conditions for Self-Archiving. 


\title{
Learning Lessons from Software Implementation Projects: An Exploratory Study
}

\author{
Karen Macdonald Heaton ${ }^{1}$, Walter Skok ${ }^{2}$, Serhiy Kovela ${ }^{2}$ \\ ${ }^{1}$ Better Gameplan Consultancy, East Sheen, London, UK \\ ${ }^{2}$ Business School, Kingston University London, UK \\ * Correspondence to: Walter Skok, Business School, Kingston University, Kingston Hill, \\ Kingston upon Thames, Surrey KT2 7LB, UK. E-mail: wskok@kingston.ac.uk
}

\begin{abstract}
This study aims to establish whether software companies learn effectively from past implementation projects to enhance future project outcomes. Key themes of project success from existing literature, together with analysis from our deductive and inductive survey, produce a thematic framework which is subsequently used to generate recommendations for improvement of organisational learning in software projects. We conclude that inherent technological and organisational complexity in these projects results in learning outcomes that fail to address core issues sufficiently. This is mainly caused by a lack of commitment to organisational learning from projects, the difficulty in extracting meaningful lessons from complex projects and the organisations' short-term business models focused on sales generation at the expense of improving project outcomes. Recommendations are made for reshaping organisational strategy by introducing cross-functional responsibility for project outcomes, committing to project learning and knowledge management across business units, and targeted competency development for project managers.
\end{abstract}

Keywords: project management, knowledge management, software projects, project complexity, organisational learning.

\section{Introduction}

Exponential advances in technology over the past 20 years have created a dynamic and complex new world of software projects presenting companies with an ever-growing array of management challenges. The ability of software companies to adapt to these new challenges thus becomes crucial for organisational competitive advantage and survival. Yet, despite current common acknowledgment of this notion software projects keep failing, which is succinctly expressed in "Cobb's paradox" - "we know why projects fail; we know how to prevent their failure - so why do they still fail?" (Skok and Legge, 2002). This research explores the challenges companies face in software implementation projects and understand if learning from such projects can improve their ability to deliver. 


\section{Literature review}

Despite multiple efforts from a wide community, such as extensive publication of academic papers and textbooks, establishment of training and accrediting bodies, and ongoing mentorship and advice, there continues to be a low success rate in IT projects (Ghobadian, 2010; Winter et al., 2006a; PPMN, 2014). This notion is supported by research from Sauer and Cuthbertson (2003), McManus and WoodHarper (2008), Standish Group (2005) and the Project Management Institute (2015), who collectively conclude that project success rates in the US, UK and Europe have improved slightly in the past decades, but continue to be in the region of $9-36 \%$. The figures are extremely low considering the level of investment in the IT industry. For instance, in banking alone, IT-related spending already accounted for around 15-20\% of total costs at the turn of the century (Davis, 2000) and considering the ever-growing importance of IT infrastructure and applications for business, the percentage is likely to increase. In absolute values, Lodge et al. $(2014,2015)$ report that there has been an upward trend in IT spending in banking worldwide with total figures across North America, Europe, and Asia-Pacific projected at US $\$ 196.7$ billion in 2015 , a $4.6 \%$ increase over 2014 , and a further growth of $4.7 \%$ and 4.6\% is expected in 2016 and 2017 respectively. The situation of massive and steadily increasing spending on IT projects calls for a better understanding of why these projects keep failing, but more specifically whether learning from those projects could produce better results for that spending.

For software companies, applying the recommendations from project success/failure research can be difficult for several reasons. Firstly, the existing "project success factors in IT" studies are based on varied population and project typologies with differing detail and granularity. Sauer \& Cuthbertson (2003) processed 421 responses from UK project management professionals, Standish Group (2005) report represents over ten years of data from 3,000 sampled members and covering 50,000 multidisciplinary projects in the US, whilst McManus \& Wood-Harper (2008) examine 214 information system projects EU-wide. Secondly, whilst there is general agreement on a definitive set of factors determining project outcomes from these studies (Table 1), they do not suggest what organisational capabilities should be improved in order to address those factors. 
Cooke-Davies (2002) surveyed 23 European organisations over a six-year period and goes some way to describing the 12 "real" success factors in terms of organisational capability. In particular, the author highlights the importance of learning for continual improvement, which is the core topic of this research (see Table 2). Meanwhile a worldwide survey of 522 project managers across various industries was conducted by Williams (2004 and 2008) which established that while organisations are believed to learn from their projects, in practice the way they do is perceived as ineffective by those project managers in charge. Williams (2008) also found that "the least successful aspect of learning is the transfer of lessons within an organisation, particularly from the project team to the organisation"; a point also identified by Hartmann and Doree (2015). Savolainen and Ahonen (2015) offer further support to the notion by pointing out that knowledge flow throughout the project "breaks off when a project manager does not continue as the project manager after the sales phase", whilst Zhao et al. (2015) conclude that "cross-project knowledge transfer is affected differently by the capabilities of and governance efforts by the source and recipient teams". We thus believe that uncovering the reasons behind this in projects where software systems are sold and implemented by the same organisation would produce findings potentially instrumental in reducing the number of such software projects failing.

\section{*****INSERT TABLE 2*****}

\section{Key themes from literature review}

Based on a literature review spanning over 60 sources including papers in peer-reviewed academic journals, industry publications and standards such as Project Management Body of Knowledge (Project Management Institute, 2015) the authors identified the following four themes for further investigation into project learning (and shown diagrammatically in Figure 1):

- Project management (PM) education;

- Project complexity;

- Knowledge management;

- Organisational learning. 
We now expand these themes in more detail.

\subsection{PM education}

For over 50 years, the PM discipline has enjoyed steady growth, providing a well-recognised professional occupation and career path for industry practitioners worldwide (Kerzner and Saladis, 2009). Yet, project success rates generally remain relatively low. At the same time the increasing use of projects as a mechanism for implementing corporate strategy and business change has moved the profession beyond the traditional industries of engineering, construction and defence.

Morris (2000) reviewed project management theory spanning ten years of research and concluded that there was still scope for further study of the competency development for project managers to complement new research in knowledge management and organisational learning.

Coupled with the blending of technological, cultural, social and organisational factors, increased project complexity is recognised by academics and practitioners alike. Questions are being asked whether current Project Management Bodies of Knowledge (PMBOK) are fit for purpose in today's world of complex projects (Hartman and Ashrafi, 2004; Morris et al., 2006; Price, 2010; Shenhar \& Dvir, 2007). In response to these questions in 2004 - 2006 the UK government funded a research network Rethinking Project Management Network (RPMN) that attempted to "develop a research agenda aimed at extending and enriching mainstream project management ideas in relation to the developing practice" (Winter and Smith, 2006a). RPMN researchers found that the growth in business adoption of project management had not been matched by a commensurate growth in the underpinning content of PMBOK endorsed by Project Management Institute (PMI), Association for Project Management (APM) and Office of Government Commerce (OGC). It was noted that while the PMBOK content had traditionally focused on "hard" (engineering) systems methodology, current challenges to project success in ascendance are increasingly "soft" (e.g. project complexity, organisational behaviour and culture, contextual nature of project environments). Augmented with other contributions notably from Sauer and Reich (2009) who focused specifically on IT projects, 
RPMN further concluded that to reach a qualitatively new level of improvement in project success rates, managing complicated projects with technical toolkits was no longer sufficient. Instead the discipline, together with existing PMBOKs has to be expanded in a number of additional directions specifically: a) action; b) economic, social and emotional process of projects; c) broader conceptualisation of projects; d) project complexity, and e) knowledge process based on practitioners' reflective practice. Studies by Ojiako et al. (2011) as well as Ramazani and Jergeas (2015) support this recommendation.

Winter et al. (2006b) also argued that classifying projects as primarily business in nature would invite management disciplines such as strategy, operations management, and management of change to be applied in managing these projects. They proposed two perspectives for projects: "project as a value creation process" and "project as organisational change". Authors of this study have used the same project perspective to focus on learning from business projects, which deliver value and/or change through the implementation of software solutions. Morris et al. (2006) and Shenhar and Dvir (2007), on the other hand, in reviewing the content of PMBOKs, call for the adoption of a more interpretivist approach to understanding the complexities in projects, to move the educational focus away from (already well defined) project execution and control processes to the wider contextual and business environment impacting the project.

Software implementation projects are often complex and poorly understood (Skok and Legge, 2002) as they bring unique challenges ranging from currency in technology and naturally high velocity of the software industry to dynamic client/supplier business environment impacting the priorities in project planning and execution. As such, the generic PMBOKs, may not provide sufficient contextual guidance in project management methods to improve the management of today's projects (Smyth and Morris, 2007). This fully applies to the typology of complex projects being examined in the study. 


\subsection{Project complexity}

Managing technology projects is a multi-disciplinary exercise spanning the domains of engineering, administration, and sociology. Ivory and Alderman (2005) advise viewing such projects as complex systems where technology, individual workforce and organisational perspectives are tightly intertwined and failure is more likely to result from the mix rather than from any of its individual components separately. To tackle systems' complexity in projects, studies such as the one by Remington and Pollack (2007) propose an "order - chaos" continuum where understandable and clearly structured systems reside on the "order" end whilst those with more complex structures involving opaque levels of inter-connections gradually move into "chaos" resulting in a higher uncertainty of outcomes. They suggest the following dimensions of complexity apply to the management of technology projects:

- Technical - multiple teams at different locations and time zones, building different components, some issues potentially being discovered as the project moves forward;

- Structural - project contains multiple elements (around 5-6), which are complex together but not individually;

- Directional - goals, paths and agendas are not closely aligned and thus result in conflicts;

- Temporal - project suffers from shifting environmental and / or strategic objectives often as a result of influences beyond the direct control of the project team.

Vidal et al. (2011) have developed the idea by proposing a different view of project complexity based on project systems size, variety, interdependencies, and context, but also gravitated towards broader technical and organisational dimensions.

Complexity in general, introduces greater levels of uncertainty and risk in projects, which increases the challenges for Project Managers to deliver their projects successfully. The process of learning reusable lessons from such projects is thus also made more difficult (Williams et al., 2005).

The typology of software implementation projects being examined here reflects the unavoidable interaction between vendor and client that is more complex than a simple seller-buyer relationship in a retail environment. It is useful to regard the project delivery as a temporary partnership or quasi- 
organisation consisting both of the vendor's and client's people and processes. This includes diverse skill sets, personal and political agendas and often, where teams are virtual, differing languages, time zones and corporate cultures. Hence, complex sets of system dynamics emerge and interact.

A simple representation of a conjoined project environment is presented in Figure 3, demonstrating a single software vendor and client. The high level of possible connections and loops in this network often results in a substantially higher level of delivery risk.

\subsection{Knowledge management}

One of the earliest and most straightforward techniques for transferring project information is the “project post-mortem" originally proposed by Boddie (1987), where financial and organisational commitment is deemed as important for efficient learning as is the openness and cooperation of individuals involved in the project. Further developments of this lessons learned theme can be found in Schon (1983), Weick (1995) and Smith and Winter (2010) where projects are seen as socially constructed entities with knowledge management being a form of organisational sense making occurring through engagement and contributions from reflective practitioners.

Gustafsson and Wikstrom (2005) shift their view more towards the tacit aspect of knowledge management by regarding a project as a phenomenon that has both rational (stable and isolated processes that are clearly structured and controlled through a predetermined series of steps) and intuitive constituents. Whilst the rational part can be easily codified to harvest and retain knowledge, the accumulation of knowledge gained from the intuitive part can only be achieved through the experience of managing more projects.

Bresnen et al. (2004) also indicate a growing interest in tackling the tacit element of knowledge accumulated by project managers as reflected in increased prominence of "Communities of Practice" both in academic literature and business practice. Narrative approach is widely used here to explore, make sense of the issues, and learn them. Cicmil (2005) offers a conceptual framework, PM-MP, to capture in-depth and properly deconstructed knowledge from projects. She proposes five domains of 
project knowledge: context; content; organisational behaviour; communication and project congruence. This framework forms part of the information needs for the research questions. While Sandhawalia et al (2010) present their Knowledge-Dynamic Feedback Model (K-DFM) to address the long term knowledge requirements within software projects.

Savolainen and Ahonen (2015) stressed the importance of continuity in acquiring and utilising knowledge at all stages of the project, by ensuring that project managers consistently involve themselves in the process, whilst Zhao et al. (2015) proposed a model positing that "cross-project knowledge transfer is influenced by project teams' transfer capabilities, relationship and context, as well as project task context”.

The two key points are:

- Active management of both tangible and tacit knowledge is key to enabling efficient accumulation and subsequent distribution of expertise required for project delivery

- Senior Management commitment to learning is essential for effective knowledge management and, consequently, for improving project success rates for an organisation.

\subsection{Organisational learning}

Early direct references to organisational learning originate from strategy theory and acknowledge an organisation's ability to continually "renew its competences" as a dynamic capability (Teece et al., 1997) conferring competitive advantage, particularly in a changing business environment. Organisational learning was also noted as one of the "real" success factors in projects by CookeDavies (2002) and as one necessary to better manage uncertainty in projects by Atkinson et al. (2006). Project Management Maturity Models endorsed by OGC and PMI also highlight continuous learning

as the highest level of project management maturity within an organisation, acknowledging its importance in accumulating and preserving the expertise gained in delivering various projects (Kerzner, 2000).

Love et al. (2005) argue that to effectively facilitate learning in project-based environments certain conditions must be in place: there must be a clear understanding of the unique characteristics and 
operational environment of the project; continuous learning should be embedded within organisational culture; synergy should be created through collective actions in support of learning. Similarly, Reich (2007) describes an appropriate climate for learning as one consisting of knowledge channels, team memory and knowledge risks.

Challenges to the ability of organisations to learn are noted by Hodgson and Cicmil (2006) who argue that contemporary project management methods and processes are "antithetical to those that are conducive to the spread of organisational change and learning". Caniels (2009), on the other hand, describes issues occurring through poor levels of trust arising from asymmetry in power levels between different groups of stakeholders, both within and across organisations - this latter notion has particular relevance to software companies and their relationship with clients in implementation projects. Shore (2008) cites organisational culture and systematic biases such as "illusion of control" and "selective perception" as impediments to discussing project failures, whilst Hall and Sapsed (2005) point out that challenges to knowledge management in organisations may come from individuals who, lacking appropriate motivation and encouragement to share, "hoard" knowledge and prevent it from being assimilated elsewhere. Many of the above challenges were addressed in a study by Duffield and Whitty (2015) where a model, SyLLK, was proposed to enable project organisations to "conceptualise how they learn from past project experiences and distribute successful project knowhow across an organisational network of elements such as individual learning, culture, social, technology, process and infrastructure".

\section{Research design}

\subsection{Research objectives and questions}

The focus of this research is to examine and understand how software companies perceive project learning, what is learned, and how is it utilised to manage future software implementation projects in order to identify ways of improving practice.

The literature review identified a number of themes reflecting aspects of sustained improvement for project success rates, which were subsequently used to formulate a set of objectives and research 
questions presented in Figure 2. The questions helped to structure a series of in-depth interviews with industry practitioners with extensive experience in managing software implementation projects and reflected their view on how the theory and practice of organisational learning aligned in real-life. The mix of deductive and inductive analysis of data obtained through the interviews resulted in an expanded version of the original thematic framework (Figure 6). The expanded framework was subsequently used to generate a better understanding of the dynamics of learning from software implementation projects.

\subsection{Unit of analysis}

The research attempts to analyse the phenomenon of poor IT project success rates by identifying specific contextual factors existing in a common typology of projects, i.e. software implementation projects and a common type of company, i.e. software company, that develops, sells and implements its products (Figure 3). We attempt to validate a link between low levels of learning from software projects and poor project success rates.

\section{*****INSERT FIGURE 2*****}

\subsection{Population sample and data collection}

A mix of homogenous and theory-based sampling techniques was used to support the research objectives. The authors followed Love's (2005) view, that in situations where enhancement of organisational learning comes from understanding the unique characteristics and operational environment of the organisation, it is helpful to restrict the scope of organisation typology to reduce the numbers of organisational characteristic variables. Thus the companies selected were from within the technology sector, with multi-stream revenues from the implementation and live support of software products in excess of $£ 1 \mathrm{~m}$, and taking more than a year to complete. The typology of projects for the study can be defined as "business projects, where complex business systems which add value or create organisational change (e.g. customer relationship management / banking systems, etc.) are implemented" (Winter et al., 2006b). Homogeneity of project managers was achieved through selecting individuals with extensive experience (10 years or more) of the project and organisation typology outlined above (see Table 3). 


\section{${ }^{* * * *}$ INSERT FIGURE $3^{* * * *}$}

Data for the study was collected as a cross-sectional series of nine digitally recorded semi-structured "Emotionalist and Subjectivist" interviews (Eriksson and Kovalainen, 2008. p.79), whereby the interview was used to capture the interviewees' experiences, trying to effectively understand "the how" of learning from projects.

\subsection{Analysis methods}

Initially a pilot interview was conducted to establish that the interview questions met the information needs of the research questions. Concept-driven coding (Ritchie and Lewis, 2003, pp. 224, 228) was then used to generate meanings from the main body of the data collected. Dataset familiarisation initially occurred through the interview process itself and was followed by listening to the audio version of the interview while checking the accuracy of the verbatim interview transcript. Data reduction was performed iteratively on the individual transcripts prior to, during and after coding. Each iterative change in the transcripts was captured through version control of the electronic document in order to maintain an audit trail of the changes. In the process, several new themes emerged and were subsequently incorporated into the original conceptual framework, resulting in analysis that was both deductive and inductive.

\section{*****INSERT TABLE 3****}

\subsection{Limitations and transferability of the findings}

Data limitation within this study could arise from the respondents' potential bias towards their belief in project learning by virtue of agreeing to participate in the study. To address this a number of questions in the interview were formulated specifically to mitigate such bias (see questions 3, 6, and 8 in Table 4 in Appendix A).

In terms of transferability, the deliberately broad criteria for selecting target software companies and projects for analysis make the findings potentially applicable to any software vendor that is involved in these types of projects. 


\section{Findings}

The four themes forming the original thematic framework and three additional themes that emerged from the analysis of the interviews are now discussed.

\subsection{Project complexity - factors increasing the uncertainty and risk in projects}

It was established that internal changes in the vendor's organisation affecting the management layer of the project delivery team could lead to changes in morale and therefore cause increased uncertainty and risk (Respondents A, B, C, F). Project size, as well as readiness and capability of both the vendor and client undertaking the project (Respondents A, C, E, G, I) were also established as impacting complexity in projects. Lack of project understanding on the client side often manifested itself in unclear and constantly changing requirements and project scope (Respondents C, D, G, I), which are factors cited by numerous studies into project failures referred to earlier in this paper.

The established technical aspects of complexity in the context of software implementation projects were described as:

- Maturity, i.e. a release with few or no other prior deployments can be a much greater challenge than the one with a large existing customer base;

- Interoperability with client's other systems;

- Quality, ease of retrieval and understanding of client user requirements and data;

- Ease of support and maintenance.

\subsection{PM education - perception and use}

The respondents agreed that the popular PMBOKs (PMI, OGC, etc.) are generally beneficial in providing all project team members with a common basis for understanding the mechanics of a generic "project" and its associated glossary of terms or "jargon" (Respondents C, D, F, G). However, some respondents (G, H, I) described the PMBOK-based processes as "too prescriptive", "too general" and "too heavy", stressing their conviction that the skill of a project manager is not in the mindless application of textbook rules but in applying the prescribed methods proportionately to the specific 
needs of individual projects. This confirms Crawford et al. (2006) findings that "one best way" is no longer seen as appropriate for managing complex projects and that PMBOK-based education plays only a supporting role in today's project environment. Finally, the concept of viewing projects as "value-creating systems" and "business endeavours involving IT where technology is utilised to derive business value by effectuating organisational change" (Winter et al., 2006b) appears to be well understood and applied in practice (Respondents A, H, I). These findings complement the RPMN (Winter and Smith, 2006a) recommendations to categorise projects and roles to support targeted education to improve project management education.

\subsection{Knowledge management - strong management support required}

Most knowledge assets were understood by respondents as codified and accessible via various electronic mechanisms such as intranet sites, wiki pages, electronic data management systems (EDMS) and project management systems (Respondents A, C, D, F, H). In recognising that these mechanisms were useful, they acknowledged that management support is still required to ensure these mechanisms are maintained and contain current, quality information to transfer knowledge effectively. Despite the understanding that experience was imperative to build competent project managers, respondents were unaware of formal mechanisms for experiential knowledge sharing between project managers (except for Respondent A, whose organisation supported team members spending time together).

The respondents commonly acknowledged that knowledge management was generally supported via communities of practice (COPs) for specific project roles (e.g. functional consultants, technical consultants or experts involved in product development and support operations), but little of this existed among project managers. At this level of organisational hierarchy several factors were notably at play:

- Knowledge hoarding - often occurring in "structurally" complex projects, where multiple third-party organisations are involved (Respondent D, E, F, I); 
- Competitive / blame culture - often a major obstacle to learning from unsuccessful projects and a barrier to creating effective teamwork and knowledge sharing across the organisation (Respondent A).

\subsection{Organisational learning - often lacking continuous commitment and proper dissemination}

It was established that software companies do not routinely and rigorously assimilate learning from projects, neither within the divisions involved in managing projects, nor within the organisation at large (Respondents A, C, D, G, H, I). Equally, it emerged that where lessons are learnt, it is often unclear who the recipient of the reports is and how the information is subsequently used (Respondents A, C, D, G, I), which confirms findings by Williams $(2004,2008)$ highlighted by the literature review. None of the respondents had experience of project management maturity models being used in any of the software companies they had worked for throughout their careers, although most companies would have some form of procedures for managing projects. A single respondent (Respondent F) had experienced a maturity model (Software Delivery Maturity Model (SDMM) being used, but the practice was only confined to the Development and Support division, not the project management organisation. This demonstrates the software companies' perception on where their capabilities lie, hence the lack of commitment to continued organisational improvement in managing projects.

Several respondents suggested that useful learning from projects is thus either experiential (Respondents C, D, G) or embryonic (Respondent A). Respondent B commented that "we learn, but we don't get better... we learn in the sense we know that it is going to happen".

Describing the barriers to organisational learning respondents referred to the lack of operational maturity in young software companies (Respondent $\mathrm{C}, \mathrm{H}$ ), internal silos and power bases within the organisation, disaggregation of operational chain, and lack of top management support (Respondents A, B, C, D, G, I). Respondent C was also convinced that the heavy focus on future revenue projections by top management meant useful organisational learning was not seen as a worthwhile investment and therefore was not integrated in the project management process and organisational culture at large. 
"Financial pain" was cited by respondents (A, C, D, E, I) as possibly the only factor that could trigger top management's interest in learning from failed or failing projects, whereby the resources would be allocated to "fix" or arrest the problem, but not necessarily secure a commitment to continued operational improvement. Other relevant problems cited were ineffective learning processes that do not "fit" the project typology (Respondents A, E, I) and the loss of knowledge when a project team disbands.

In terms of how the learning process was occurring in projects it was established that there was a unidirectional flow of information between the sales and implementation phases (Figure 4), with a critical feedback loop missing (Respondents B, C, D, G, I). Also mentioned was a gap in information and knowledge transfer during the handover between the sales process and the start of project implementation (Respondents A, B, C, D, I), resulting in unnecessary revisiting of client instructions and expectations and a steep learning curve for the project implementation teams.

\section{$* * * * *$ INSERT FIGURE 4*****}

The types of lessons learnt were related to the software development process, as well as the configuration and operation of the software itself, and were routinely fed back to the Development teams (Respondents B, D, E, and F). Problems occurring early in the implementation lifecycle arose due to a lack of continuity between sales and project teams during the handover (Respondents A, B, C, $\mathrm{D}, \mathrm{G}, \mathrm{I})$.

\subsection{Emergent themes}

\subsubsection{Clients' impact on projects}

One of the emergent themes generated from the data analysis describes clients' impact on projects, where the respondents described their experience as follows:

- 'Clients' experience in managing projects varies enormously depending on the project typology, as well as maturity of their processes and their industry/sector at large" (Respondents A, G); 
- "Client's ability to easily understand technical detail of the solution is often inversely proportional to the degree of outsourcing in their operations" (Respondents E, F);

- "The quality and availability of information required for the successful solution deployment is determined by the client's ability to manage and maintain quality business data, which in turn can depend on the degree of outsourcing in their operations" (Respondent F, I);

- "Appropriate and sufficient levels of client sponsorship and influence, hence the internal power or "clout" needed to implement a solution affecting many business functions, can affect how a project operates and, if inappropriate, the delivery of business benefits can be impeded" (Respondent B, C).

Options open to software vendors on how to tackle the above issues depend on the stage of the sales process, relationship between the vendor and prospective client, as well as the client's reliance on the vendor for implementation advice. Unfortunately, project managers often lack authority to undertake client assessments during pre-sales activities due to the pre-sales process being owned by another team and reluctance of decision makers on both sides to acknowledge client side risks. As Respondent A put it “... would we genuinely asses their (the client's) ability to fulfil those (contractual) obligations...? That's probably a step too far for us as a software company... We can't force them and say: "you're not ready for this yet, come back in a year and when you've done this, then we'll sell you some software". The respondents also agreed that undertaking client capability assessments could be used by Sales teams to adjust contract terms to properly reflect the "client risk" on the project (Respondent A, B, C, D, F, I).

\subsubsection{Balance of power between software vendor and client}

The analysis also identified a theme manifested by a number of issues around the varying power balance between software vendor and client throughout the project implementation lifecycle. In the pre-sales phase, the client generally commands considerably higher power in the relationship, as they are financing the commissioning of the solution. However, as soon as the solution is commissioned and the implementation moves along, the client's power gradually transfers to the vendor due to depth of understanding of various technical aspects of the project and increasing switching costs 
(Respondent A, B, C, D, and F). Thus, the vendor often has more understanding of what is required to implement the solution by the end of pre-sales phase than the client themselves. This potentially creates a moral dilemma for the vendor's Sales team who can arbitrarily decide which of the information they possess can be released to complete the sale; this is reflected by Caniels (2009) who describes challenges to learning arising from such power asymmetry. To that effect, in the words of Respondents $A$ and $G$ “...the client ultimately, has the most to lose from signing a contract under conditions of imperfect information".

\subsubsection{Commercial realities in projects}

The typical commercial drivers and business models in software companies have emerged as an important factor impacting project learning. Typical organisational structures experienced by the respondents contain divisions such as Sales, Consulting, Development and Support, all managed as separate units and operating on different business metrics for revenue, profitability and margin. For instance, sales targets would be the key metric for Sales, Consulting would be preoccupied with project profitability and resource utilisation, Support would look at profitability of ongoing maintenance and customer retention levels, and Development would be looking at delivery timeframes and spend (normally a capitalised expense allocated to a budget for product development and influenced by organisational strategy).

Problems arise because many of those divisions interact throughout the project lifecycle and these interactions are not always beneficial to project outcomes. For example, Morris (2010) found that the seeds of failure are often sewn in the pre-sales phase. A simple implementation lifecycle shown in Figure 5 demonstrates the responsibilities of business divisions throughout the life of the project.

\section{******INSERT FIGURE 5*****}

Ownership of the client relationship in the pre-sales process, during which the solution is designed and sold to the client, rests with Sales who generally pass the signed contract and responsibility for it to Consultancy, who manage it in conjunction with the client. Sales teams receive commissions when the 
contract is signed, but rarely are there linkages to the outcomes or profitability of the project implementation (Respondents A, B, C, D). Compensation calculations vary from case to case, but are generally linked to the software license fees. Equally, teams involved in project implementation are rarely responsible for the post-implementation support and maintenance of the solution they pass on to Support.

Hence a complex picture emerges of team and ownership changes where responsibility transfers both within and between the software vendor and client side throughout the project, causing consequences in loss of project knowledge and barriers to learning. This often negatively impacts the relationship building and expectation setting with the client.

These issues are attributed to top management's attitude, which is forward looking and focused on sales revenues (Respondents A, C, G, I) not project outcomes, and is especially characteristic of stock exchange-listed software companies where revenues and expected free cash flows are used for market valuations. In the words of those respondents: “Isn't it interesting that poorly delivered projects will impact your support organisation big time... and if only a certain amount of focus was here on the project and delivering a good quality project... then your support will become easier" (Respondents A, C, G, I).

Addressing this by engaging additional resources (e.g. an experienced project manager) during the presales phase is seen as an unnecessary burden on the budget in all but strategically important projects (Respondents A, C).

\section{Summary of findings}

Analysis of the primary data provided insight into the context-specific challenges to learning from complex implementation projects as experienced by project professionals in software companies. The expanded thematic framework combining the original themes identified in the literature review and those that emerged from the primary data analysis is presented in Figure 6.

The findings are as follows: 
- Project complexity in software implementation projects is determined by a number of factors including project size, technical complexity, capability and commitment of both vendor and client to actively collaborate on the project, together with the intensity and scale of changes in user requirements and project management team throughout the project lifecycle.

- Project management education in its current form is useful, as it provides a common reference of terms and processes for all project team members and can be used by project managers to tailor generic methods to the needs of specific projects. Therefore, senior management needs to recognise that organisational capability builds from the competences of its resources, and consider the development of project managers in a similar vein to a senior business manager, requiring industry experience, training and an appropriate development plan.

\section{******INSERT FIGURE $6 * * * *$}

- Effective knowledge management requires codifiable and accessible knowledge assets, active management support to ensure that knowledge is kept up to date and of adequate quality, as well as effective mechanisms for sharing that knowledge among project managers, most of which were found lacking. Software companies' focus as its knowledge assets is the codification of technical and procedural product-related information, as opposed to project management-related information. Necessary pre-conditions for broader (project) knowledge management were not widely adopted nor embedded in the organisational culture of software companies.

- Software companies do not routinely and rigorously assimilate learning from projects, the learning is mostly experiential and non-systemic, and when the lessons are learnt, often there is no clear process for disseminating the new expertise within the organisation. Here factors such as lack of operational maturity, disaggregation of supply chain, internal silos and power bases within the organisation, all negatively affect the organisation's ability to learn.

- Top management's commercial focus is on financial targets (as a result of the alignment of compensation packages to company valuations and revenues), which treats anything not directly related to sales, development and support as non-priority at best. Consequently, a 
project learning-related cost is more of an unwanted expense item in a single project's budget, than part of the overarching organisation's effort to develop generic capability of delivering better projects. The lack of a feedback loop from the implementation team to the sales team means an opportunity to improve the sales process based on the expertise from projects delivered is missed, resulting in recurring mistakes that could otherwise be easily avoided.

- The shifting "client vs. vendor" power balance introduces complex dynamics in managing the delivery of software projects through team changes and the ownership and responsibility transfers between teams within and across vendor and client organisations. Because divisions such as Sales, Consulting, Development and Support are often managed as separate business units and operate on different business metrics with targets often inherently competing with the targets of other divisions this complicates communication, project delivery and learning.

- Factors determining a clients' impact on project outcomes include their previous experience in similar projects, maturity of their processes, ability to understand the technical detail of the solution and how they manage and maintain quality business data required for the implementation. Assessing the client's ability to facilitate the project delivery is deemed as important as assessing the vendor's ability to deliver it, however this is rarely done in practice.

\section{Conclusions}

The objectives for this study were to explore the type, applicability and effectiveness of assimilation of any lessons learned across the organisation, with reference to software development companies. We uncovered context-specific factors contributing to the problems of learning, where certain elements in the organisational setup and strategy of those companies were responsible for poor learning outcomes. We found that PMBOK-based education plays a supporting role in project management practice. Whilst indicative of best practices, it lacks context specific advice and may be unsuitable for managing complex software implementation projects. An effective Project Manager requires skills similar to those of senior business managers and this type of software business would benefit by acknowledging this and developing these competences as a strategic priority. 
In the absence of a strategy and practical provisions for enabling and enforcing the accumulation of project lessons and sharing them across the organisation, we found that costly mistakes, that could otherwise be easily avoided, were repeated. This could be addressed by crystallising and demonstrating the inherent financial value of targeted organisational project learning. Using such an approach, one could aggregate learning from individual projects and produce an understanding of a broad typology of projects, clients and their associated risk profiles, and subsequently assign "risk price tags" to complex projects.

To support the above, the study concludes:

1. Software implementation projects need to improve the communication links between pre-sales and live operations support. Project learning should begin early in the project lifecycle and occur regularly and organisation-wide. To provide for this, sales commissions must be structured in a way to ensure wider cross-functional responsibility for successful project outcomes.

2. Software companies should engage more with the client to achieve better transparency of the joint organisations' ability to deliver the project. They should do this by undertaking capability assessments to ensure there are sufficient skills in project implementation expertise, thereby reducing the complexity, risk, and costs in current and future projects.

3. To enable project knowledge to be shared and utilised more widely than the immediate project team, software companies should expand their strategic focus and consider resource and knowledge-based views of competency development of its project managers.

It would be impractical to assume that changes to the organisational strategy stipulating the redesign of financial compensation models, joint capability assessments and targeted project management competency development, could be implemented overnight without wider industry acceptance of the associated benefits to project outcomes. However, an innovative and forward thinking organisation may consider that this pays dividends in savings on software implementation costs, increased organisational capability in project delivery and better retention of highly experienced project 
managers. All of the above will require a significant shift of thinking in the boardrooms of software companies.

\section{References}

Ambler S. 2014. 2013 IT Project Success Rates Survey Results [Online]. Available at <http://www.ambysoft.com/surveys/success2013.html> [Accessed 7 Aug 2015].

Atkinson R, Crawford L, Ward S. 2006. Fundamental uncertainties in projects and the scope of project management, International Journal of Project Management, 24(8): 687-698.

Boddie J. 1987. The project post-mortem (learning from engineering mistakes), Computerworld, 21(49):77-82.

Bresnen M, Endelman L. et al. 2004. A community perspective on managing knowledge in project environments, in: Love P, Fong P, Irani Z. 2004. Management of Knowledge in Project Environments, Elsevier Butterworth-Heinemann.

Caniels M. 2009. The Moderating Effect of Trust on the Relationship between Power Asymmetry and Organisational Learning, International Conference on Organizational Learning, Knowledge and Capabilities [Online]. Available at <http://www.feweb.vu.nl/olkc2009/Papers/5CMarjoleinCaniels.pdf> [Accessed 27 April 2015].

Cicmil S. 2005. Reflection, participation and learning in project environments: a multiple perspective agenda, in: Love P, Fong, P, Irani Z. 2005. Management of Knowledge in Project Environments, Elsevier Butterworth-Heinemann.

Cicmil S, Williams T. et al. 2006. Rethinking project management: Researching the actuality of projects, International Journal of Project Management, 24(8): 675-686.

Cooke-Davies T. 2002. The "Real" Success Factors on Projects, International Journal of Project Management, 20(3): 185-190.

Crawford L, Morris P. et al. 2006. Practitioner development: From trained technicians to reflective practitioners, International Journal of Project Management, 24(8): 722-733.

Davis S. 2000. Bank Mergers: Lessons for the Future, St. Martin's Press [Online]. Available at <http://dx.doi.org/10.1057/9780230509399> [Accessed 27 April 2015].

Duffield S, Whitty J. 2015. Developing a systemic lessons learned knowledge model for organisational learning through projects, International Journal of Project Management, 33(2): 311-324.

Eriksson P, Kovalainen A. 2008. Qualitative Methods in Business Research, Sage Publications Ltd.

Ghobadian A. 2010. Growing gulf between managers and research, Financial Times, 31 May [Online]. Available at <http://www.ft.com/cms/s/0/18108dca-6c4b-11df-86c500144feab49a.html\#axzz3YWYYoYSt> [Accessed 27 April 2015].

Gustafsson M, Wikstrom K. 2005. Managing Projects through reflection, in: Love P, Fong P, Irani Z. 2004. Management of Knowledge in Project Environments, Elsevier Butterworth-Heinemann.

Hal J, Sapsed J. 2005. Influences of knowledge sharing and hoarding in project based firms, Management of Knowledge in Project Environments, Elsevier Butterworth-Heinemann. 
Hartman F, Ashrafi R. 2004. Development of the SMART Project Planning Framework, International Journal of Project Management, 22(6): 499-510.

Hartmann A, Doree A. 2015. Learning between projects: More than sending messages in bottles, International Journal of Project Management, 33(2): 341-351.

Hodgson D, Cicmil S. 2006. Making Projects Critical, Palgrave MacMillan.

Ivory C, Alderman N. 2005. Can project management learn anything from studies of failure in complex systems? Project Management Journal, 36(3): 5-16.

Kerzner H. 2000. Applied Project Management: best practices on implementation, in Cooke-Davies, T. (2002) The "Real" Success Factors on Projects, International Journal of Project Management, 20:185190.

Kerzner H, Saladis F. 2009. What Executives need to know about Project Management, Wiley \& Sons.

Lodge G, Jedher J, Zhang H. 2014. IT Spending in Banking: A Global Perspective, Celent [Online]. Available at <http://www.celent.com/reports/it-spending-banking-global-perspective-2> [Accessed 15 May 2014].

Lodge G, Jedher J, Zhang, H. 2015. IT Spending in Banking: A Global Perspective, Celent [Online]. Available at <http://www.celent.com/reports/it-spending-banking-global-perspective-2> [Accessed 15 May 2014].

Love P, Fong P, Irani Z. 2004. Management of Knowledge in Project Environments, Elsevier Butterworth-Heinemann.

McManus J, Wood-Harper T. 2008. A lesson in Project Failure [Online]. Available at <www.bcs.com> [Accessed 10 November 2013].

Morris P. 2010. Research and the future of project management, International Journal of Managing Projects in Business, 3(1): 139-146.

Morris P. 2000. Researching the Unanswered Questions of Project Management [Online]. Available at <www.indeco.co.uk> [Accessed 7th June 2010].

Morris P, Crawford L. et al. 2006. Exploring the role of formal bodies of knowledge in defining a profession - the case of project management, International Journal of Project Management, 24(8): 710-721.

Ojiako U, Ashleigh A. et al. 2011. Learning and teaching challenges in project management, International Journal of Project Management, 29(3): 268-278.

Price M. 2010. Improving the management of projects in the UK - a call for collaboration, Project Manager Today, pp. 8-11.

Project Management Institute, 2015. Capturing the Value of Project Management, Pulse of Profession [Online]. Available at <http://www.pmi.org/ /media/PDF/learning/pulse-of-the-profession-2015.ashx> [Accessed 7 Aug 2015]. 
Ramazani J, Jergeas G. 2015. Project managers and the journey from good to great: The benefits of investment in project management training and education, International Journal of Project Management, 33(1).

Reich B. 2007. Managing Knowledge and Learning in IT Projects: A Conceptual Framework and Guidelines for Practice, Project Management Journal, 38(2): 5-17.

Remington K, Pollack J. 2007. Tools for Complex Projects, Gower Publishing.

Ritchie J, Lewis, J. 2003. Qualitative Research Practice, Sage Publications Ltd.

Sandhawalia BS, Dalcher D. 2010. Knowledge Flows in Software Projects:

An Empirical Investigation, Knowledge and Process Management, 17(4): 205-220.

Sauer C, Cutherbertson C. 2003. The State of IT Project Management in the UK in the UK 2002-2003, [Online]. Available at

<http://www.bestpracticehelp.com/The_State_of_IT_Project_Management_in_the_UK_2003_2004.pd f> [Accessed 15 May 2014].

Sauer C, Reich B. 2009. Rethinking IT project management: Evidence of a new mindset and its implications, International Journal of Project Management, 27(2): 182-193.

Savolainen P, Ahonen J. (2015) Knowledge lost: Challenges in changing project manager between sales and implementation in software projects, International Journal of Project Management, 33(1): 92-102.

Schon D. 1995. The Reflective Practitioner, in: Smith C, Winter M. (2010) The Craft of Project Shaping, International Journal of Managing Projects in Business, 3(1): 46-60.

Shenhar A, Dvir D. 2007. Project Management Research - The Challenge and Opportunity, Project Management Journal, 38(2): 93-99.

Shore B. 2008. Systematic biases and culture in project failures, Project Management Journal, 39(4): 5-16.

Skok W, Legge M. 2002. Evaluating Enterprise Resource planning (ERP) systems using an Interpretive approach, Knowledge and Process Management, 9(2): 72-82.

Smith C, Winter M. 2010. The Craft of Project Shaping, International Journal of Managing Projects in Business, 3(1): 46-60.

Smyth H, Morris P. 2007. An epistemological evaluation of research into projects and their management: methodological issues, International Journal of Project Management, 25(4): 423-436.

Standish Group, 2005. Chaos Rising, Standish Group International [Online]. Available at <www.thestandishgroup.com> [Accessed 15 May 2014].

Teece D, Pisano G, Shuen, A. 1997. Dynamic Capabilities and Strategic Management, Strategic Management Journal, 18(7): 509-533.

Vidal L, Marke F, Bocquet, J. 2011. Measuring project complexity using the Analytic Hierarchy Process, International Journal of Project Management, 29(6): 718-727. 
Weick K. 1995. Sensemaking in Organisations, in: Smith C, Winter M. 2010. The Craft of Project Shaping, International Journal of Managing Projects in Business, 3(1): 46-60.

Williams T. 2004. Identifying the hard lessons from projects - easily, International Journal of Project Management, 22(4): 273-279.

Williams T. 2008. How Do Organisations learn from projects - And Do They? IEEE Transactions on Engineering Management, 55(2): 248-266

Williams T, Ackerman F. et al. 2005. Learning from Project Failure, in: Love P, Fong P, Irani Z. 2005. Management of Knowledge in Project Environments, Elsevier Butterworth-Heinemann.

Winter M, Smith C. 2006a. Rethinking Project Management, EPSRC Network 2004-2006 [Online]. Available at <http://www.ronrosenhead.co.uk/wp-content/uploads/2008/05/rethinking-projectmanagement1.pdf $>$ [Accessed 10 November 2014].

Winter M, Smith C. et al. 2006b. Directions for future research in project management: The main findings of a UK government-funded research network, International Journal of Project Management, 24(8): 638-649.

Zhao D, Zu, M. et al. 2015. Examining the factors influencing cross-project knowledge transfer: An empirical study of IT services firms in China, International Journal of Project Management, 33(2): 325-340. 


\begin{tabular}{|lccc|}
\hline \multicolumn{1}{|c}{$\begin{array}{c}\text { Reason for project failure / } \\
\text { challenged projects }\end{array}$} & Standish & Sauer \& & McManus \\
\hline Requirements management & Group & Cuthbertson & \& Wood \\
\hline End user input / management of & Yes & Yes & Yes \\
\hline Lack of executive support & Yes & Yes & Yes \\
\hline Technology incompetence & Yes & Yes & Yes \\
\hline Lack of resources & Yes & Yes & Yes \\
\hline Unrealistic timeframes & Yes & Yes & Implicit \\
\hline Vendor management / performance & Yes & Yes & Yes \\
\hline Strategy / project alignment & & Yes & Yes \\
\hline Management understanding of managing projects & & Yes & Yes \\
\hline
\end{tabular}

Table 1 IT project failure factors 


\begin{tabular}{|c|c|}
\hline $\begin{array}{l}\text { Terry Cooke- } \\
\text { Davies (2002) }\end{array}$ & The "real" success factors in projects \\
\hline Factor 1 & Adequacy of company-wide education on the concepts of risk management \\
\hline Factor 2 & Maturity of an organisation's processes for assigning ownership of risks \\
\hline Factor 3 & Adequacy within which a visible risk register is maintained \\
\hline Factor 4 & Adequacy of an up-to-date risk management plan \\
\hline Factor 5 & Adequacy of documentation of organisational responsibilities on a project \\
\hline Factor 6 & Keep project (or stage duration) as far as below 3 years ( 1 year is best) \\
\hline Factor 7 & Allow changes to scope only through a mature scope change control process \\
\hline Factor 8 & Maintain the integrity of the performance measurement baseline \\
\hline Factor 9 & $\begin{array}{l}\text { The existence of an effective benefits delivery and management process that } \\
\text { involves the mutual cooperation of project management and line } \\
\text { management }\end{array}$ \\
\hline Factor 10 & $\begin{array}{l}\text { Portfolio and programme management practices that allow the enterprise to } \\
\text { resource fully, a suite of projects that are thoughtfully and dynamically } \\
\text { matched to the corporate strategy and business objectives }\end{array}$ \\
\hline Factor 11 & $\begin{array}{l}\text { A suite of project, programme and portfolio metrics that provides direct "line } \\
\text { of sight" feedback on current project performance and anticipated future } \\
\text { success, so that project, portfolio and corporate decisions are aligned }\end{array}$ \\
\hline Factor 12 & $\begin{array}{l}\text { An effective means of "learning from experience" on projects, that combines } \\
\text { explicit knowledge with tacit knowledge in a way that encourages people to } \\
\text { learn and to embed that learning into continuous improvement of project } \\
\text { management processes and practices }\end{array}$ \\
\hline
\end{tabular}

Table 2 The "real" success factors in IT projects 


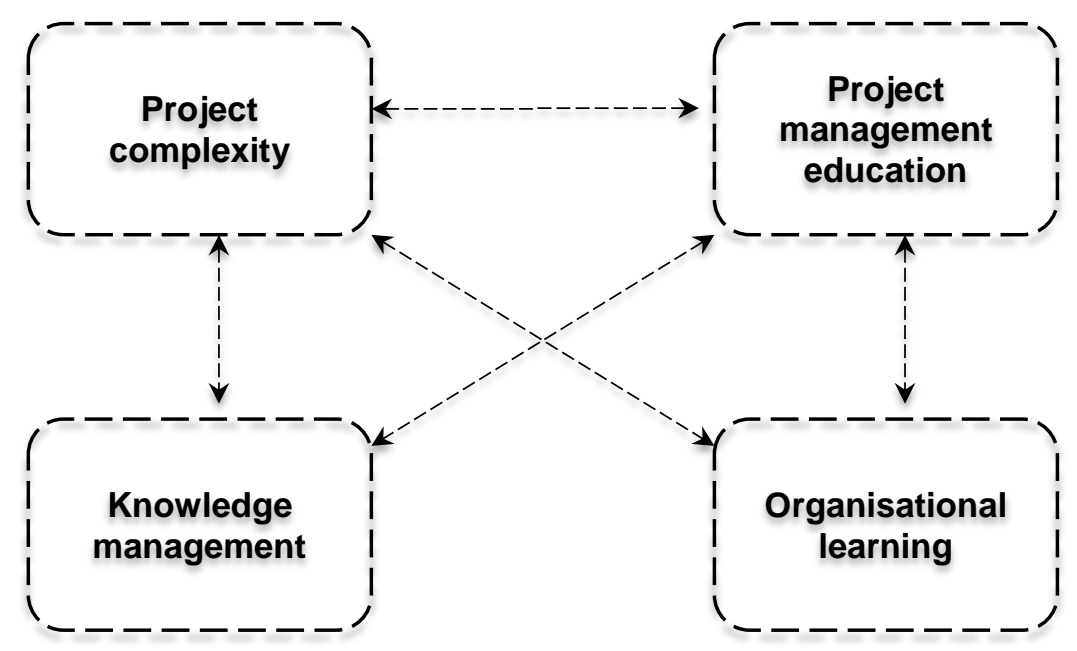

Figure 1 Original thematic framework: key aspects of sustained improvement for projects 


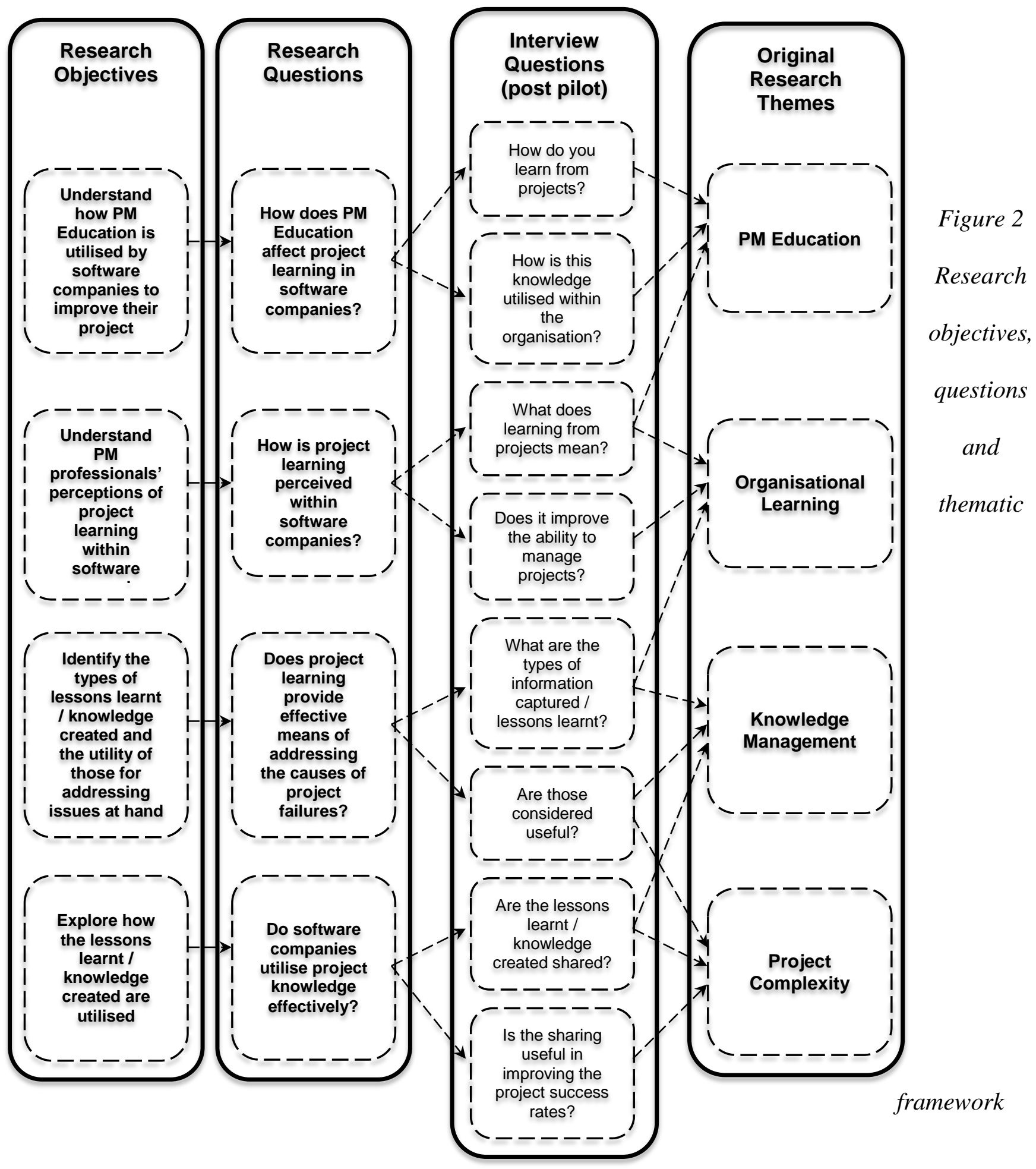




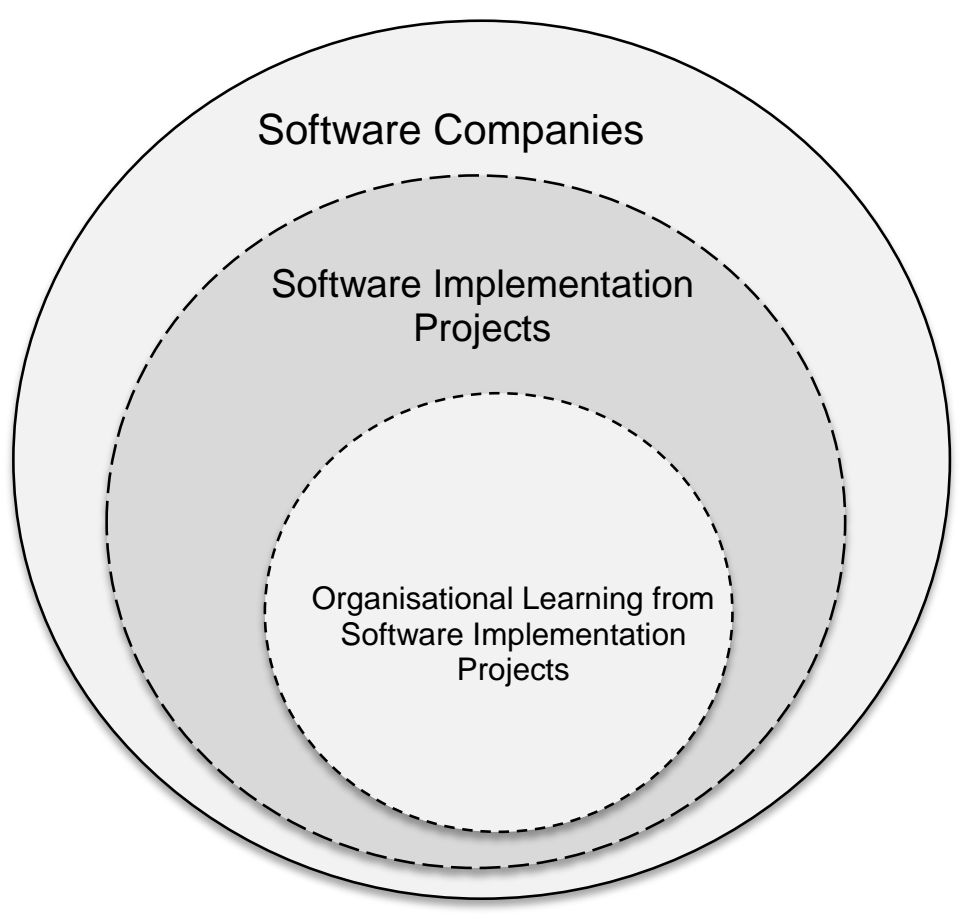

Figure 3 Unit of Analysis 


\begin{tabular}{|c|c|c|c|}
\hline $\begin{array}{c}\text { Respondent } \\
\text { profile }\end{array}$ & Roles & $\begin{array}{c}\text { Project } \\
\text { experience }\end{array}$ & Software company experience \\
\hline Respondent A & $\begin{array}{l}\text { Professional } \\
\text { Services Director }\end{array}$ & 20 years & $\begin{array}{l}\text { Worldwide, } 44,000 \text { customer sites, } \\
\$ 2.3 \text { bn revenue, privately held }\end{array}$ \\
\hline Respondent B & $\begin{array}{l}\text { Programme } \\
\text { Manager }\end{array}$ & 20 years & $\begin{array}{l}\text { Worldwide, } 300 \text { customers, privately } \\
\text { held, } 150 \text { staff }\end{array}$ \\
\hline Respondent $\mathrm{C}$ & $\begin{array}{l}\text { Senior Project } \\
\text { Manager }\end{array}$ & 20 years & $\begin{array}{l}\text { Worldwide, NASDAQ, } 370,000 \\
\text { customers, } \$ 6.8 \text { bn revenue }\end{array}$ \\
\hline Respondent D & Project Manager & 15 years & $\begin{array}{l}\text { Worldwide, NASDAQ, 3,000 customers, } \\
\$ 239 \mathrm{~m} \text { revenue }\end{array}$ \\
\hline Respondent E & Project Manager & 15 years & $\begin{array}{l}\text { Worldwide, NASDAQ, } 100+\text { customers, } \\
\$ 264 \mathrm{~m} \text { revenue }\end{array}$ \\
\hline Respondent F & $\begin{array}{l}\text { Senior Technical } \\
\text { Manager }\end{array}$ & 15 years & $\begin{array}{l}\text { Worldwide, SEK listed (Sweden), 1,000+ } \\
\text { customers, } \$ 264 \mathrm{~m} \text { revenue }\end{array}$ \\
\hline Respondent $\mathrm{G}$ & Project Manager & 10 years & $\begin{array}{l}\text { Worldwide, SIX listed (Switzerland), } \\
1,000+\text { customers, } \$ 5.37 \text { bn revenue }\end{array}$ \\
\hline Respondent $\mathrm{H}$ & Managing Director & 10 years & $\begin{array}{l}\text { UK nationwide, } 15+\text { customers, start-up } \\
\text { web-development, privately held }\end{array}$ \\
\hline Respondent I & Project Manager & 10 years & $\begin{array}{l}\text { EMEA-wide, AIM listed, 150+ } \\
\text { customers, } \$ 22 \mathrm{~m} \text { revenues }\end{array}$ \\
\hline
\end{tabular}

Table 3 Demographic breakdown of companies and respondents 


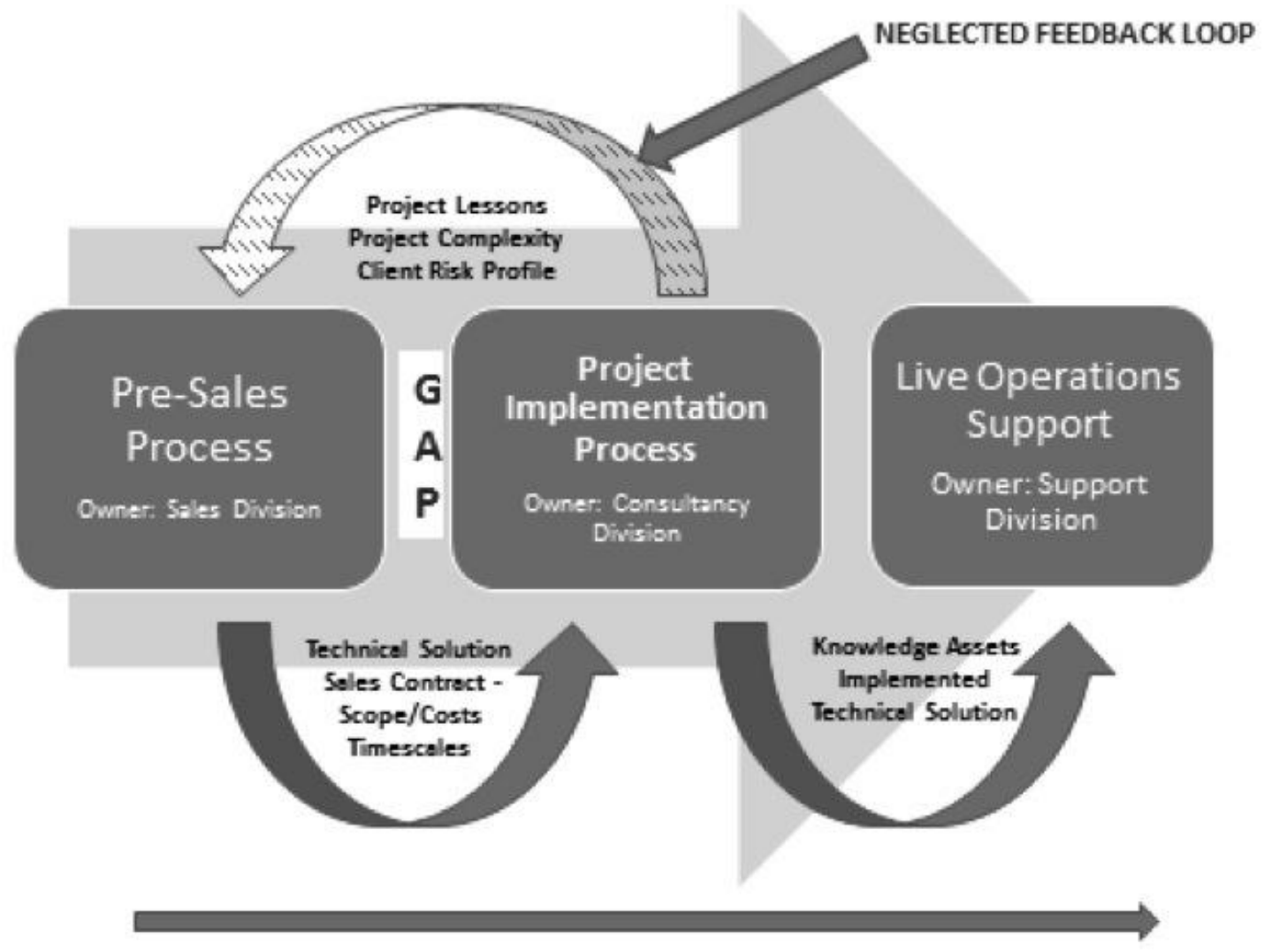

Figure 4 Project information flow 


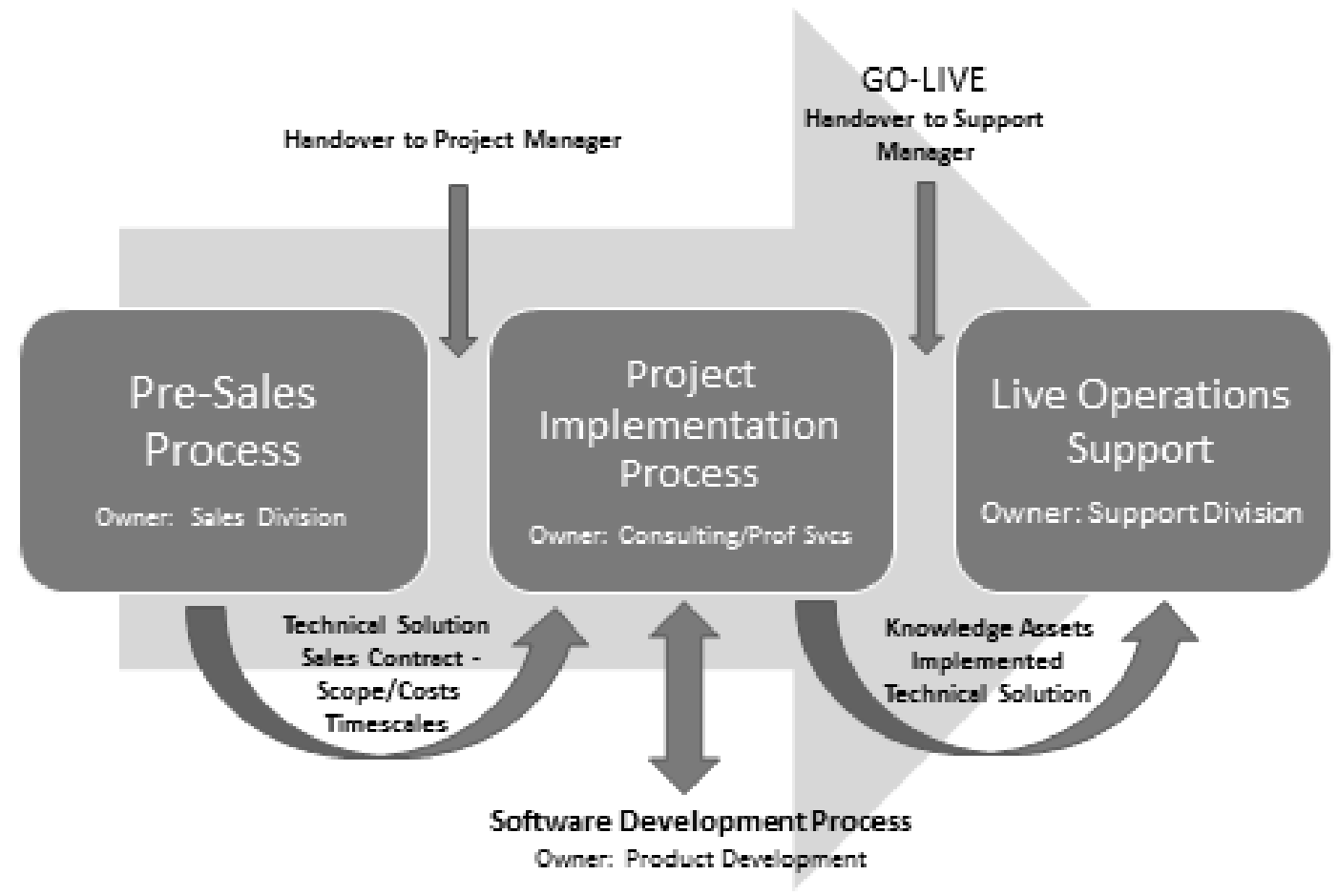

Figure 5 Software Vendor's Project Lifecycle 


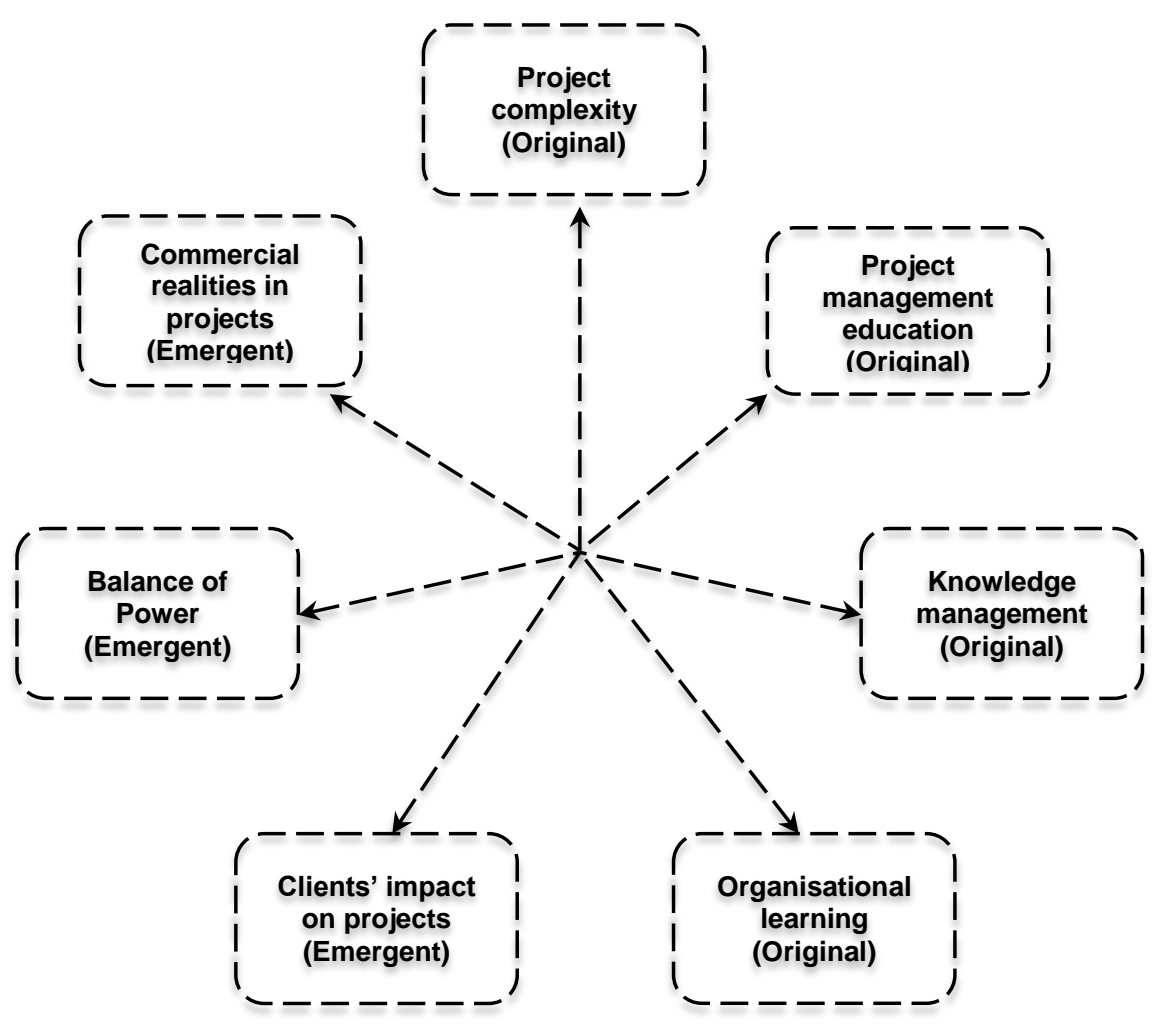

Figure 6 The thematic framework revised 
Appendix A. Information needs for the research

\begin{tabular}{|c|c|}
\hline Interview Questions & Information needed / what the researcher wants to know \\
\hline $\begin{array}{l}\text { 1. How do you learn from } \\
\text { projects? }\end{array}$ & $\begin{array}{l}\text { What organisational or personal factors does the participant } \\
\text { consider influence how learning occurs? }\end{array}$ \\
\hline $\begin{array}{l}\text { 2. How widely is this learning } \\
\text { accepted in the organisation? }\end{array}$ & $\begin{array}{l}\text { What mechanisms, standards or procedures are in place? Is it } \\
\text { organisation-wide? }\end{array}$ \\
\hline $\begin{array}{l}\text { 3. What does learning from } \\
\text { projects mean? }\end{array}$ & $\begin{array}{l}\text { Participants' perceptions of projects within their organisation } \\
\text { and their link with learning and knowledge }\end{array}$ \\
\hline $\begin{array}{l}\text { 4. Does it improve ability to } \\
\text { manage projects? }\end{array}$ & $\begin{array}{l}\text { Participants' understanding of the benefits to be gained from } \\
\text { learning from projects and whether or project managers' } \\
\text { education influences this. }\end{array}$ \\
\hline $\begin{array}{l}\text { 5. What types of lessons are } \\
\text { learned or information } \\
\text { gathered? }\end{array}$ & $\begin{array}{l}\text { Give examples of types of lessons learned or knowledge created } \\
\text { and how they relate to improving the participants' ability to } \\
\text { manage projects. }\end{array}$ \\
\hline $\begin{array}{l}\text { 6. Are these considered useful } \\
\text { lessons/information? }\end{array}$ & $\begin{array}{l}\text { What are the participant's views on the usefulness of what is } \\
\text { currently learned? Does this concur with that of peers or senior } \\
\text { management? }\end{array}$ \\
\hline $\begin{array}{l}\text { 7. What happens to the } \\
\text { lessons/knowledge? }\end{array}$ & $\begin{array}{l}\text { What mechanisms, standards or procedures are in place? Is it } \\
\text { organisation-wide? }\end{array}$ \\
\hline $\begin{array}{l}\text { 8. Is sharing of } \\
\text { lessons/knowledge useful? }\end{array}$ & $\begin{array}{l}\text { What are the participant's views on the usefulness of what } \\
\text { sharing lessons/knowledge? Does this concur with that of peers } \\
\text { or senior management? }\end{array}$ \\
\hline
\end{tabular}

Table 4 Information Needs for the research 